\title{
Skin Diseases Associated with the Depletion of Stratum Corneum Lipids and Stratum Corneum Lipid Substitution Therapy
}

\author{
Fitsum F. Sahle ${ }^{a, d}$ Tsige Gebre-Mariam ${ }^{d}$ Bodo Dobner ${ }^{b}$ Johannes Wohlrab ${ }^{c}$ \\ Reinhard H.H. Neubert ${ }^{a}$ \\ Departments of a Pharmaceutical Technology and Biopharmaceutics and b Pharmaceutical Chemistry, Institute of Pharmacy, \\ and ' Department of Dermatology, Faculty of Medicine, Martin Luther University of Halle-Wittenberg, Halle (Saale), Germany; \\ ${ }^{\mathrm{d}}$ Department of Pharmaceutics and Social Pharmacy, School of Pharmacy, College of Health Sciences, Addis Ababa \\ University, Addis Ababa, Ethiopia
}

\section{Key Words}

Ceramides · Cholesterol · Free fatty acids · Lipid

replenishment therapy · Skin diseases · Stratum corneum

\begin{abstract}
The skin is the largest organ of the body, whose main function is to protect the body against the loss of physiologically important components as well as harmful environmental insults. From the inside to the outside, the skin comprises three major structural layers: the hypodermis, the dermis and the epidermis. The epidermis contains four different sublayers, the stratum corneum (SC), stratum granulosum, stratum spinosum and stratum basale, where the barrier function of the skin mainly lies in the outermost layer of the epidermis, the SC. The SC contains corneocytes that are embedded in a lipid matrix existing in the form of lipid bilayers. The lipid bilayers are formed mainly from ceramides, free fatty acids and cholesterol, constitute the only continuous pathway across the $\mathrm{SC}$ and are responsible for the barrier function of the skin. However, the depletion or disturbance of SC lipids in the SC leads to a perturbation of the barrier function of the skin, and, conversely, several skin diseases such as psoriasis and atopic dermatitis are associated with the depletion of these SC lipids. Therefore, it is of paramount importance to under-
\end{abstract}

stand the interrelationship between the depletion of SC lipids and skin diseases as well as factors that affect the composition and organization of SC lipids in order to assess the potential benefit of a direct replacement of the missing SC lipids as a means of treating affected, aged or diseased skin.

(c) 2014 S. Karger AG, Basel

\section{Introduction}

The skin comprises three major structural layers: the hypodermis (the innermost layer), the dermis (the middle layer) and the epidermis (the outer layer) [1]. The hypodermis is a fatty subcutaneous layer of the skin, whereas the dermis (3-5 mm thick) is a layer of connective tissue that primarily contains fibroblasts embedded in a cellular collagen/elastin matrix that accounts for the major part of the skin's thickness [2]. The overlying epidermis comprises four different layers of cells, namely, the stratum basale $(\mathrm{SB})$, stratum spinosum (SS), stratum granulosum (SG) and stratum corneum (SC) $[3,4]$.

The SC (fig. 1) contains layers of corneocytes embedded in a lipid matrix [5-10], which is responsible for the formation and maintenance of the skin barrier against both desiccation and the penetration of xenobiotics [2].

\section{KARGER 125}

(c) 2014 S. Karger AG, Base

$1660-5527 / 14 / 0281-0042 \$ 39.50 / 0$

E-Mail karger@karger.com

www.karger.com/spp
Prof. Dr. Dr. h.c. Reinhard H.H. Neubert

Department of Pharmaceutical Technology and Biopharmaceutics

Martin Luther University of Halle-Wittenberg, Wolfgang-Langenbeck-Strasse 4 DE-06120 Halle (Saale) (Germany)

E-Mail reinhard.neubert@pharmazie.uni-halle.de 
Fig. 1. Schematic representation of the cross-section of the SC.

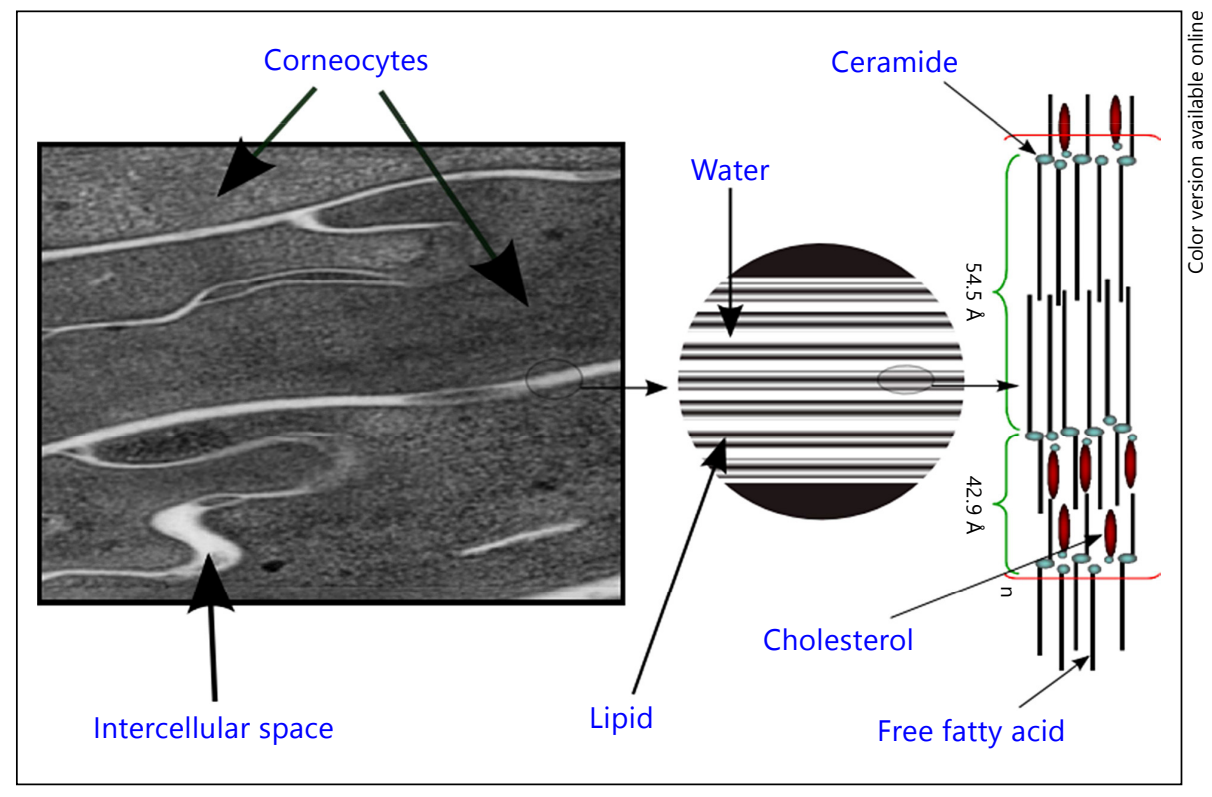

The lipid matrix contains unique lipids, mainly ceramides (CERs), free fatty acids (FFAs) and cholesterol (CHOL), which are organized in a special manner [1], and findings indicate that the depletion of these lipids results in a disruption of the barrier function of the skin [11]. Hence, a direct replacement of the missing lipids can be explored in the treatment of affected, aged and diseased skin $[2,12,13]$.

\section{Epidermis}

The epidermis (50-100 $\mu \mathrm{m})$ comprises four different layers of cells, namely, the SB, SS, SG and SC, from the inside to the outside $[3,4]$. It is a dynamic and self-renewing tissue, in which desquamation on the SC is balanced by cell growth in the lower layers of the epidermis $[4,14]$. The epidermal cells at the basal layer, the keratinocytes, proliferate and, upon leaving the layer, start to differentiate and migrate towards the surface of the skin. The terminal differentiation occurs at the SG-SC interface, during which the viable keratinocytes are transformed into corneocytes (flattened dead cells filled with keratin filaments and water) $[4,13]$.

The epidermis is a highly active site of SC lipid synthesis which is also responsive to alterations in barrier status. Injury to the skin initiates a recovery response that leads to restoration of the barrier function within hours to days, depending on the species, the age and the severity of the injury [15]. Keratinocytes, the most abundant cells of the epidermis, synthesize the lipids and other structural proteins of the SC in a controlled and regulated manner both in time and in space $[4,6]$. During migration from the basal layer to the SG, they undergo a number of changes in both structure and composition [4], that is, they synthesize precursor lipids in the SB, SS and SG, assemble the precursor lipids in the lamellar bodies (carriers of SC lipid precursors) in the SS and SG and release the contents of the lamellar bodies at the SG-SC interface by the process of exocytosis $[4,6,16,17]$.

The lamellar bodies are enriched mainly in polar lipids such as glycosphingolipids, free sterols and phospholipids as well as catabolic enzymes $[4,6]$. At the SG-SC interface, the released polar lipids undergo considerable metabolic changes and convert enzymatically into their nonpolar counterparts: phospholipids degrade into glycerol and FFAs, whereas the glycosphingolipids degrade into CERs and these nonpolar lipids finally assemble into lamellar structures surrounding the corneocytes $[4,6,16,17]$.

\section{Stratum Corneum}

The SC (10-20 $\mu \mathrm{m}$ thick) [3] protects the body against the loss of physiologically important components as well as harmful environmental insults [7]. It contains about 15 layers of corneocytes separated by a unique and complex mixture of highly ordered multilamellar lipid sheets [510] which is often referred to as a brick wall-like structure [8]. 
Fig. 2. Chemical structures of the various CER classes identified in human SC. In those CERs with $\mathrm{R}_{4}=\mathrm{OH}$, the hydroxyl group forms ester with LA giving $\omega$ esterified CERs. $n$ may vary between 2 and $22[10,32,33]$ with $\mathrm{n}=12-14[4,8]$ and 18-22 [10] are abundant in non-esterified and esterified CERs, respectively.

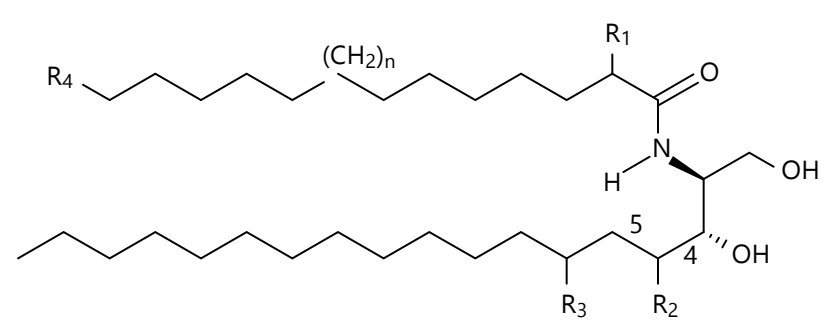

$\begin{array}{lllllllllll} & \mathrm{R}_{1} & \mathrm{R}_{2} & \mathrm{R}_{3} & \mathrm{R}_{4} & & & \mathrm{R}_{1} & \mathrm{R}_{2} & \mathrm{R}_{3} & \mathrm{R}_{4} \\ \text { CER[AS] } & \mathrm{OH} & \mathrm{H} & \mathrm{H} & \mathrm{H} & 4,5 \text {-double bond } & \text { CER[AP] } & \mathrm{OH} & \mathrm{OH} & \mathrm{H} & \mathrm{H} \\ \text { CER[NS] } & \mathrm{H} & \mathrm{H} & \mathrm{H} & \mathrm{H} & 4,5 \text {-double bond } & \text { CER[NP] } & \mathrm{H} & \mathrm{OH} & \mathrm{H} & \mathrm{H} \\ \text { CER[EOS] } & \mathrm{H} & \mathrm{H} & \mathrm{H} & \mathrm{OH} & 4,5 \text {-double bond } & \text { CER[EOP] } & \mathrm{H} & \mathrm{OH} & \mathrm{H} & \mathrm{OH} \\ \text { CER[AH] } & \mathrm{OH} & \mathrm{H} & \mathrm{OH} & \mathrm{H} & 4,5 \text {-double bond } & \text { CER[ADS] } & \mathrm{OH} & \mathrm{H} & \mathrm{H} & \mathrm{H} \\ \text { CER[NH] } & \mathrm{H} & \mathrm{H} & \mathrm{OH} & \mathrm{H} & 4,5 \text {-double bond } & \text { CER[NDS] } & \mathrm{H} & \mathrm{H} & \mathrm{H} & \mathrm{H} \\ \text { CER[EOH] } & \mathrm{H} & \mathrm{H} & \mathrm{OH} & \mathrm{OH} & 4,5 \text {-double bond } & \text { CER[EODS] } & \mathrm{H} & \mathrm{H} & \mathrm{H} & \mathrm{OH}\end{array}$

The corneocytes are surrounded by a densely crosslinked protein envelope, the so-called cornified envelope, to which a lipid monolayer (the cornified lipid envelope) is further covalently attached $[4,13]$. The cornified lipid envelope is formed from CERs with $\omega$-hydroxy groups which are capable of covalently binding to the cornified envelope proteins, especially involucrin. The lipid envelope serves as an interface between the hydrophilic corneocytes and the lipophilic multilamellar lipid sheets that are surrounding the corneocytes [18]. The corneocytes are also interconnected with other proteins called 'corneodesmosomes', which are important for the cohesion of the SC [4].

\section{Composition of the SC}

Chemically, the whole SC contains about 5-15\% lipids, $75-80 \%$ proteins and $5-10 \%$ unknown materials on a dry-weight basis [9]. However, it is the small percentage of intercellular lipids in the SC that defines the only continuous, tortuous pathway through which molecules can diffuse across the SC and plays a major role in selective permeability and skin barrier functions $[4,5,7,9,10,19$, $20]$. The very dense corneocyte envelope is impermeable to most diffusing substances so that the main penetration pathway through the SC remains the intercellular lipid lamella [20], which also plays a prominent role in dermal and transdermal drug delivery [21].

The multilamellar lipid lamellae of the SC are made of a unique complex mixture of polar and nonpolar lipids that, unlike biological membranes, is almost devoid of phospholipids $[8,9,13,22]$. Their main components are
CERs, CHOL and FFAs (predominantly long-chain and saturated), which exist nearly in equimolar amounts on a weight basis and contribute about 40-50, 20-33 and $7-13 \%$, respectively $[2,7,23]$. The other lipids in the lamellar sheets include cholesterol-3-sulfate (0-7 wt\%) and cholesteryl esters $(0-20 \mathrm{wt} \%)$ [5, 23, 24]. Nevertheless, these lipids vary with the location and depth of the skin, age, sex and the pathological state of the individual, as well as between individuals, races and seasons of the year $[5,6,25,26]$. In addition, the amount of FFAs is higher in the upper layers of the SC than in the inner layers [27].

CERs contain a sphingoid moiety [which can be sphingosine (S), dihydrosphingosine (D), phytosphingosine $(\mathrm{P})$ or 6-hydroxy-sphingosine $(\mathrm{H})$ ], linked with a longchain FFA moiety [which can be nonhydroxy (N), a-hydroxy (A) or ester-linked $\omega$-hydroxy (EO)] by an amide bond $[13,28]$. Besides, unlike other tissue CERs, SC CERs are extremely complex [4]; to date, 12 different types of free CER have been identified in human SC, which are named 'ceramide XY' where ' $\mathrm{X}$ ' represents the type of FFA moiety and ' $\mathrm{Y}$ ' represents the type of sphingoid base (fig. 2) [18, 29]. The acyl CERs (CER[EOS], CER[EOP], CER[EOD] and CER[EOH]) have a unique structure of linoleic acid (LA) linked to the $\omega$-hydroxy fatty acid moiety $[18,29]$. In essential fatty acid deficien$\mathrm{cy}$, oleate substitutes for linoleate as the predominant $\omega$-esterified species in CER[EOS] and CER[EOP], causing a profound barrier abnormality [15]. CER[NS] is expressed ubiquitously in mammalian tissues [18]. The relative percentage of each CER class proposed by various authors is different, but CER[NP] and CER[NS] are present at higher percentages than CER[AP] and CER[EOS] $[13,30,31]$.
Sahle/Gebre-Mariam/Dobner/Wohlrab/ Neubert 
Unlike their precursor membrane lipids, SC lamellar membranes contain mostly saturated FFAs of significantly longer chain length, which varies between $\mathrm{C} 16$ and $\mathrm{C} 26$. The main FFAs in the SC include palmitic acid (C16: $0)$, stearic acid (C18:0), behenic acid (C22:0), lignoceric acid (C24:0) and hexacosanoic acid (C26:0), which contribute approximately $10,10,15,25$ and $10 \%(\mathrm{~m} / \mathrm{m})$, respectively, to the total SC FFAs [20]. Other FFAs are oleic acid (C18:1, n-9), eicosapentaenoic acid (C20:5, n-3), docosahexaenoic acid (C22:6, n-3), LA (C18:2, n-6) - the most abundant polyunsaturated fatty acid - and its derivatives [ $\alpha$-LA $(\mathrm{C} 18: 3, \mathrm{n}-3), \gamma$-LA $(\mathrm{C} 18: 3, \mathrm{n}-6)$ and dihomo- $\gamma$-LA (C20:3, n-6)] as well as arachidonic acid (AA; C20:4, n-6) [32, 33]. Some odd-chain FFAs have also been identified in human SC $[30,34]$. Among the different FFAs, the C18 unsaturated and the C22 and C24 saturated are present in relatively large amounts [20,35]. All FFAs can be synthesized in the body from glucose and acetate carbon sources. However, the body is incapable of inserting double bonds beyond the $n-9$ position $[36,37]$ and, therefore, cannot synthesize the two essential FFAs LA and AA. However, AA may be converted into LA in keratinocytes in an extreme state of essential FFA deficiency [36].

In addition to the structural lipids, there are lipids on the surface of the skin that are secreted by sebaceous glands, which are referred to as the 'acid mantel' of the SC and provide the skin with 'self-sterilizing' properties [38]. The acid mantle of the SC mainly consists of triglycerides, wax/sterol esters, squalene and some FFAs [4-6, 24]. cis6-Hexadecenoic acid is the most abundant and ubiquitous lipid in human skin and has been suggested to be the most active antimicrobial lipid in skin surface lipids [38]. These lipids may also alter the endogenous lipid structure by increasing alkyl chain mobility [4].

\section{Organization of Lipids in the SC Lipid Lamellae}

The SC lipid matrix displays a refined spatial organization of the lipids into lipid lamellae that are oriented approximately parallel to the surface of the corneocytes. The uniqueness of the organization is strongly dependent on the composition of the lipid [16] and governs the permeability and barrier properties of the SC [23,39].

\section{Lamellar Organization of Lipids in the Lipid Lamellae}

Understanding the lipid matrix in the SC began with the observation of the lipid lamellae under an electron microscope [40]. Further information on the lamellar organization and lateral packing of the lipids in the lipid lamellae was obtained using the results of small-angle and wide-angle X-ray scattering techniques, respectively $[41,42]$. Later on, the results of neutron scattering were applied to elucidate the lamellar organization of the matrix [43]. However, the illustration of the lamellar organization of the lipids in the lamellae is not yet fully agreed upon, and various models describing the organization have been proposed by different authors at different times, of which some are briefly discussed in this section. Small-angle X-ray diffraction results for the human SC showed the existence of two phases, called the 'short' and 'long periodicity phases', which are approximately 60 and $130 \AA$, respectively [10, $19,22,43-45]$, and some of the models took this into consideration.

\section{The Domain Mosaic Model}

The domain mosaic model described by Forslind [42] contains a multilamellar two-phase system in which a discontinuous lamellar crystalline structure is embedded in a continuous liquid crystalline structure, which is referred to as the 'grain border' and is assumed to be the path for the permeation of both hydrophobic and hydrophilic compounds [42].

\section{The Sandwich Model}

Bouwstra et al. [41] postulated a sandwich model based on the results of small-angle X-ray diffraction and other findings. In this model, the lamellar phase contains a narrow liquid sublattice ( $30 \AA$ ) sandwiched between two wide lipid crystalline layers (50 ̊), representing the long periodicity phase of $130 \AA$. According to the authors, the wide lipid layers comprise CERs with longer-chain FFAs (C24-C26), the $\omega$-esterified CER and CHOL forming a crystalline sublattice, while the central narrow fluid lipid monolayer comprises the $\omega$-esterified unsaturated FFA chain of the $\omega$-esterified CER, CHOL and CER with a short FFA chain (C16) in hairpin conformation (fig. 3). The formation of the fluid sublattice is mainly attributed to the relatively immobile unsaturated FFA. The authors also suggested that CER[EOS], which forms the crystalline sublattice, extends all the way to the narrow fluid sublattice and plays a significant role in forming the long periodicity phase.

\section{The Single Gel Phase Model}

In 2001, Norlén [46] came up with a different model called the 'single gel phase model'. Unlike the above versions, in this model, the lipids in the lipid lamellae exist 
Fig. 3. Arrangement of SC lipids in the long periodicity phase, as proposed by Bouwstra et al. [41]. Figure from Bouwstra et al. [41].
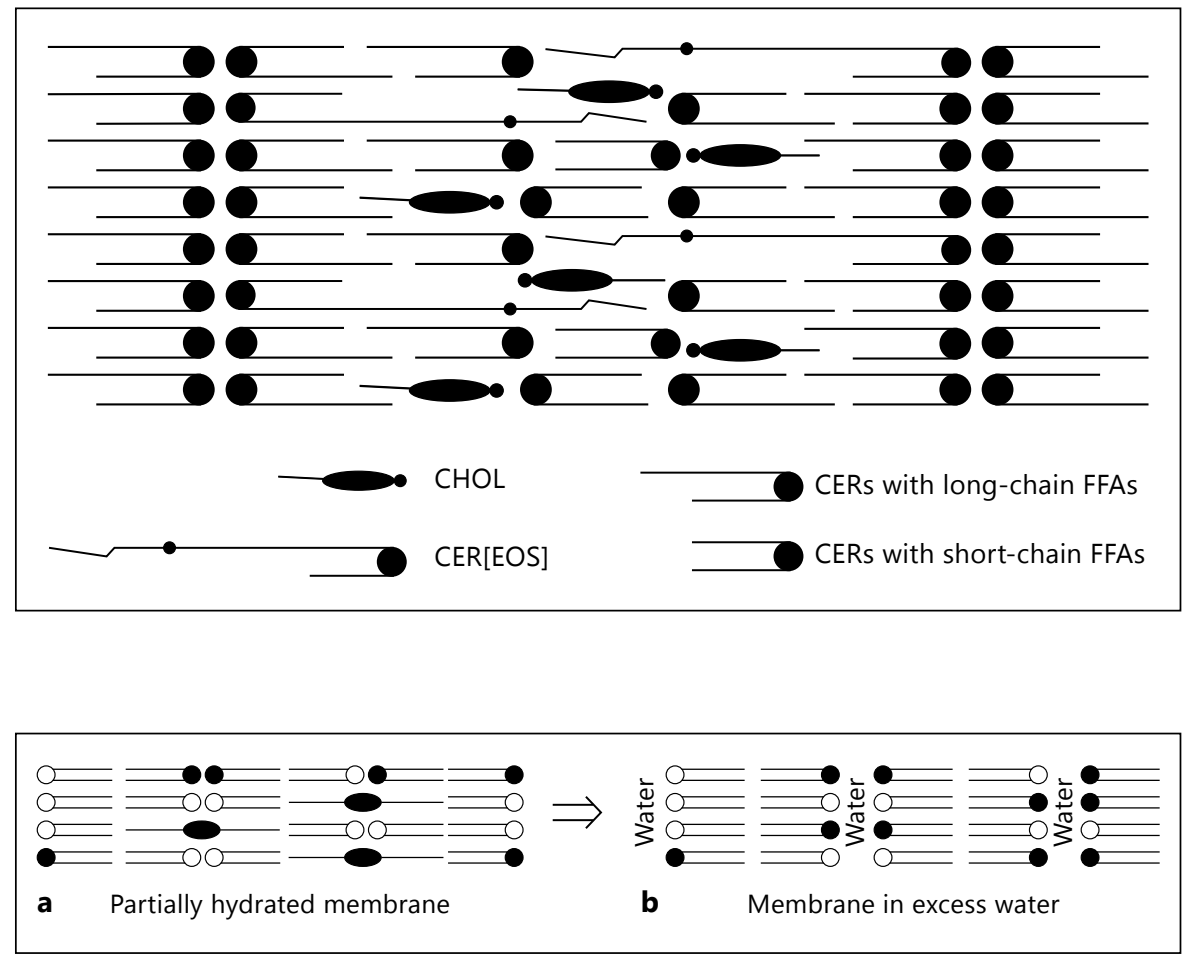

Fig. 4. Flip-flop transition of CERs from fully extended state (a) to hair pin state (b), explaining the arrangement of adjacent lamellae as described by Kiselev et al. [43]. Figure from Kiselev et al. [43]. as a single and coherent gel phase; 'gel' was defined by the author as 'a crystalline lamellar lipid structure that usually has a hexagonal hydrocarbon chain packing with rotational disorder along the lipid chain axes and usually contains some water between the lamellae'. However, although no phase boundaries exist, the single gel phase may be regarded as crystal in the CHOL-deficient areas and as extremely tightly packed liquid crystal in CHOLrich areas.

The Armature Reinforcement Model

Kiselev et al. [43], later supported by Kiselev [47], Kessner et al. [48] and Schröter et al. [45], applied a neutron scattering technique to reveal the arrangement of lipids in the SC lipid lamellae, unlike the sandwich model proposed by Bouwstra et al. [41] in which all CERs exist as hair pins (fig. 3). In this model, CER[AP] exists in a fully extended state at partial hydration of the skin and penetrates the other layers and reinforces the adhesion between the lamellae [41]. However, in fully hydrated state, the CER undergoes flip-flop transition and exists one-sided (fig. 4), explaining the structural alteration of the lamellae under hydration by excess water. In highly hydrated systems, water may exist between adjacent layers, whose thickness is dependent on the degree of humidity.
The Asymmetry Model

Recently, Norlén [49] came up with an 'asymmetry model' describing the lamellar organization of SC lipids in the SC. The author hypothesized that CER[NP] plays the key role, existing in fully extended conformation forming a 45- and 65-ångström bilayer: the 45-ångström bilayer consists of the short chain of CER[NP] (having 18 $\mathrm{C}$ atoms) and $\mathrm{CHOL}$, whereas the 65 -ångström bilayer consists of the long chain of CER[NP] (having $24 \mathrm{C}$ atoms) as the main fraction, and lignoceric and behenic acid as the main FFAs.

\section{Lateral Packing of Lipids in the Lipid Lamellae}

Besides the lamellar organization, the lateral packing of lipids in the SC determines its barrier function [4]. Depending on the distance between the hydrocarbon chains of the lipids in the lamellae, three crystalline phases are possible: the disordered phase (the liquid crystalline phase) and the ordered phases (the hexagonal phase and the orthorhombic phase) $[4,21,50]$. In the liquid crystalline phase, the distances between the hydrocarbon chains are not very well defined (with a lattice constant of $0.46 \mathrm{~nm}$ ) and exhibit a higher degree of permeability. The hexagonal packing has equally distributed hydrocarbon chains with a lattice constant of $0.41 \mathrm{~nm}$ and has medium permeability. The orthorhombic phase, on the other
Sahle/Gebre-Mariam/Dobner/Wohlrab/ Neubert 
hand, has very densely packed hydrocarbon chains which are not equally distributed in the lattice (with lattice constants of 0.41 and $0.37 \mathrm{~nm}$ ) and hence exhibit very low permeability. Various techniques have shown that the long periodicity phase of the SC mainly exhibits an orthorhombic arrangement [44], which converts into a hexagonal organization at around $40^{\circ} \mathrm{C}$ [51].

Optimum percentages of all three major classes of SC lipid are important for the formation of orthorhombic lateral packing $[4,6,8,19,20,22,39,48,52,53]$. A study by Norlén et al. [27] indicated that as one goes deeper into the SC layers, the amount of FFA decreases, which results in an increase in transepidermal water loss (TEWL). The architecture of the CER head group also affects the lateral packing of the lipids. The head groups of the phytosphingosine-based CERs, such as CER[AP], have the highest number of hydroxyl groups, which enhances the formation of hydrogen bonds in the head group region and increases the stability of the orthorhombic phase [53, 54]. Long-chain FFAs have stronger van der Waals interactions, promoting the orthorhombic lateral packing [4, 10,53]. A study by Caussin et al. [53] showed that porcine skin has a lower percentage of phytosphingosine-based CERs than human skin, and relatively shorter-chainlength FFAs that mainly result in hexagonal lateral packing. In contrast, cholesterol-3-sulfate may lead to a reduction in lattice density and, consequently, to an increase in SC permeability [4].

\section{Synthesis of SC Lipids}

For a better understanding of the etiology of several skin diseases that are associated with the depletion or disturbance of SC lipids, the various processes involved during SC lipid synthesis are briefly discussed.

CERs are synthesized de novo by the action of serine palmitoyltransferase, which catalyzes the conversion of palmitoyl CoA and L-serine into CERs in the epidermis [55]. During their synthesis, the different CER species are modified at the 1-hydroxy position to either glucosylceramide species by glucosylceramide synthase or to sphingomyelin species by the transfer of phosphorylcholine from phosphatidylcholine. Following the sequential formation and sequestration of the CER precursors, they are secreted from lamellar bodies into the SG-SC interface and undergo extracellular hydrolysis to free CER species $[2,56]$. Therefore, the myriad of CER species are generated nearly exclusively via two main pathways: through degradation of glucosylceramides, catalyzed by

SC Lipid Replenishment Therapy $\beta$-glucocerebrosidase, and through hydrolysis of sphingomyelin catalyzed by sphingomyelinase, which are preceded by extrusion of the SC lipids at the SG-SC interface [2, 57-60]. In contrast, ceramidase hydrolyzes CERs into shpingophosphorylcholine and FFA [55, 60]. Moreover, although both glucosylceramides and sphingomyelins are used as sources of CERs, it is not yet clearly understood as to which CER class results from which precursor. Uchida et al. [57] suggested that sphingomyelin is mainly hydrolyzed to yield CER[AS] and CER[NS].

All nucleated layers of the epidermis are active sites of SC lipid synthesis, except the biosynthesis of sterol, which takes place more in the lower epidermis under basal conditions [2,61]. The synthesis of sphingolipids increases with epidermal differentiation [2], and hence the most undifferentiated layers of the epidermis mostly contain membrane lipids such as phospholipids [56], whereas the lamellar bodies in the differentiated keratinocytes are mainly filled with glucosylceramides, $\mathrm{CHOL}$ and phospholipids [56].

The lysosomal degradation of the various glycosphingolipids involves the nonenzymatic cofactors, the socalled saposins (SAP) or sphingolipid activator proteins. There are four SAPs (SAP A-D) that are obtained by proteolytic cleavage and glycosylation of a common precursor, prosaposin (pSAP) [59]. The activity of $\beta$-glucocerebrosidase and sphingomyelinase is stimulated by SAP C and SAP D, respectively. SAP D also stimulates acid ceramidase. Hence, pSAPs function as important modulators of the tissue concentration of CERs by the dynamic balance of the three sphingolipid hydrolysis enzymes $\beta$-glucocerebrosidase, sphingomyelinase and ceramidase, which are localized in lamellar granules [59, 60]. Like CERs, most of the sterols and fatty acids accounting for the intact cutaneous barrier are also synthesized within the epidermis, using a number of lipid catabolic enzymes such as phospholipase A, triacylglycerol hydrolase, steroid sulfatase and $\beta$-glucosidase [62-64].

Cutaneous CHOL synthesis is influenced neither by dietary CHOL nor by circulating CHOL levels. HMG CoA reductase (3-hydroxy-3-methylglutaryl CoA reductase) catalyzes the conversion of HMG CoA to mevalonic acid, a rate-limiting step in CHOL biosynthesis. HMG CoA reductase activity is dependent both on the total quantity of the enzyme present and on its activation state, which is modulated by a covalent reversible phosphorylation-dephosphorylation process where the dephosphorylated form of the enzyme is in active state [64].

In healthy skin, a perturbation of the skin barriers initiates a sequence of events that rapidly results in the re- 
turn of lipids to the SC and the restoration of its barrier function. These events include the instant secretion of preformed lamellar bodies from the SG into the SG-SC interface, an increased synthesis of $\mathrm{CHOL}$, sphingolipids and fatty acids in the epidermis, and an increased formation of new lamellar bodies by SG cells as well as their fast release at the SG-SC interface. Following a disruption of the barrier, the increase in CHOL and fatty acid synthesis in the epidermis occurs within 1-2 h, whereas the increase in sphingolipid synthesis needs $6 \mathrm{~h}$ or more [65].

Studies have shown that inhibiting the synthesis of any of the above three lipids delays restoration of the barrier function [65-67]. Besides, interestingly, the barrier's repair rates become normalized following the provision of the corresponding exogenous lipids. However, arguably, Mao-Qiang et al. [68] reported that an inhibition of the synthesis of CHOL and sphingolipids at a time accelerates barrier recovery in mice after acetone treatment or deficiency in essential FFAs.

The extent of transepidermal water flux also acts as a signal that regulates epidermal lipid synthesis: following abrogation of the barrier function of the skin with acetone, occlusive membranes prevented the characteristic increase in epidermal lipid synthesis, whereas an increase was observed in animals covered with a vapor-permeable membrane [63].

\section{Factors Affecting the Composition and Organization of SC Lipids}

As summarized below, there are several external and internal factors that affect the composition and organization of lipids in the SC $[4,69,70]$.

\section{External Factors}

Studies have shown that exposure to external factors such as chemicals used for cleansing and sanitation purposes, environmental pollutants, some pharmaceutical ingredients and some physical adversities may affect the composition and organization of SC lipids. Treatment of the skin with some chemicals such as acetone and ethanol causes barrier disruption due to extraction of SC lipids [71, 72]. Imokawa et al. [73] reported that the application of 5\% SDS aqueous solution to human forearm skin resulted in a chapped and scaly SC without any inflammatory reaction. Besides, a depletion of intercellular lipids such as CHOL, cholesterol ester, FFAs and sphingolipids was observed. The degree of the barrier disruption is dependent on the nature of the chemical and the degree of exposure. As a simple example, a study has shown that, unlike with acetone, treatment of the SC with petroleum ether resulted in a modest level of barrier disruption, owing to its poor extraction toward the polar lipids, sphingolipids and sterols [71].

Apart from these chemicals, there are over 85,000 chemical pollutants in the human environment that may act as contact allergens or irritants causing allergic or nonallergic contact dermatitis. Among those chemicals, metals, fragrances, preservatives, botanicals and paraphenylenediamine are considered the most significant [74].

Exposing the skin to physical insults such as elevated heat and moisture may alter the composition and organization of SC lipids. It is well known that an increased temperature leads to increased sweating and causes high water loss, skin dryness and pruritus [74]. Contrarily, as has been reviewed by Rawlings and Matts [75], subjects living in a dry climate, as compared with subjects in a humid climate, have much stronger barrier function and less dry skin due to increased CER levels and elevated desquamatory enzyme levels. Rogers et al. [76] have shown that there is seasonal variation in the level of SC lipids, with a higher percentage of SC lipids during summer, which depletes dramatically during spring and even more during winter. They also observed that the ratio of CER[EOS] linoleate to CER[EOS] oleate decreased dramatically in winter, which might affect SC flexibility and desquamation; furthermore, during summer, the relative levels of palmitic and palmitoleic acids were increased, whereas the level of lignoceric acid was decreased. However, during each season, the relative proportion of the major SC lipid classes as well as TEWL remained unchanged. Exposure of the skin to types of radiation such as UV may cause the destruction of microorganisms colonizing the skin, and some of them may act as superantigens, which may exacerbate skin lesions [74].

\section{Internal Factors}

Besides external factors, there are some internal factors such as age and mental state that affect the composition and organization of lipids in the SC. Several studies have shown that the levels of all major SC lipids, in particular CERs, decrease with increasing age [76, 77]. Jin et al. [78] reported that SC CERs decrease by approximately $10-15 \%$ per decade after the age of 20 years. Rogers et al. [76] showed that the level of CER[EOS] linoleate is de-
Sahle/Gebre-Mariam/Dobner/Wohlrab/ Neubert 
pleted with aging, which might reduce SC flexibility and increases the process of desquamation. They also showed that the total lipid levels decreased by approximately $30 \%$, which the authors attributed to the slower keratinocyte metabolism at an old age, leading to a decreased biosynthetic capacity. However, despite the decreased level of total SC lipids, the ratios of each of the major lipid classes, of the individual CER species as well as of TEWL remained unchanged.

A study by Altemus et al. [79] showed that acute psychosocial and sleep deprivation stress disrupts skin barrier function homeostasis in women, in whom, according to the authors, the disruption is related to the stress-induced changes in cytokine secretion. Other studies have also shown that stress exacerbates skin disorders [80-83].

Some other factors such as diet can also contribute to changes in the composition and organization of SC lipids. LA and AA are essential FFAs which are required for the synthesis of the long-chain acyl CERs, and a deficiency in these lipids results in a disruption of the SC lipid composition [15].

\section{Skin Diseases and Associated Perturbations of the SC Lipid Composition}

The depletion or disturbance of the major lipids in the SC (which can be caused by various environmental and physical factors such as soap, dry air and age) is thought to be one of the etiological factors producing dryness and barrier disruption in skin conditions $[4,69,70]$. As a result, the skin loses water and becomes dry, cracked and fissured and allows the entrance of allergens, toxins and microorganisms that can inflame and irritate the skin. The inflammation, in return, may cause further disruption of the barrier function, closing the vicious circle [84]. It may also lead to other skin conditions such as severe dryness, itching and scratching that can further lead to secondary skin infections such as herpes, molluscum, warts, staphylococcus, streptococcus, pseudomonas, fungus, yeast and tuberculosis. Depleted SC lipids may also be associated with eczema, common dry skin, excessively washed skin as well as other dry and sensitive skin situations such as chapped lips, hand and leg eczemas [70]. A deficiency in n-6 essential FFAs such as LA, $\gamma$-LA and AA may also lead to inflammatory skin conditions [15].

Conversely, over the last three decades, numerous findings have shown that there is a marked depletion of SC lipids in patients with some skin diseases such as psoriasis, atopic dermatitis $(\mathrm{AD})$, ichthyosis and xerosis [24,
$69,85,86]$. Some of the common pathogenetic changes in the SC in various skin diseases as well as associated changes in the SC lipid composition are summarized in table 1.

Interesting to mention here is that in most of the cases (e.g. psoriasis), the depletion of the SC lipids is localized to the lesional epidermis $[55,59,69,86]$. However, Macheleidt et al. [87] reported that in patients with $\mathrm{AD}$, although the lesioned site is more greatly affected than the nonlesioned epidermis, the normal-looking site has a reduced level of SC lipids in comparison with healthy skin. In addition, some authors reported that there is a direct relationship between the severity of a skin condition and the degree of SC lipid depletion $[55,69,88]$.

\section{Skin Diseases and SC Lipid Substitution Therapy}

In normal circumstances, if the barrier function of the skin is abrogated, a repair sequence is rapidly initiated with an increased synthesis of all the SC lipids to reinstate homeostasis $[67,89,90]$. The rates of lipid synthesis might not be the same, and it was shown that the synthesis of CHOL and FFAs is faster than that of sphingolipids [67, 89]. However, in some disease conditions, the rate of synthesis of these lipids is compromised and rapid replenishment of the depleted SC lipids might not be possible, resulting in an impaired barrier function of the skin. Thus, several studies have indicated that there are various ways by which the impaired functions of the skin can be restored. The approaches include direct replenishment of the missing lipids or their analogues or the administration of agents that facilitate the production of the lipids in vivo.

\section{Direct SC Lipid Substitution Therapy}

The barrier function of the SC is highly reliant on the lipid composition of the SC. The SC lipid lamellae should contain the right type and proportion of SC lipids to fulfill their function. Any disturbance of any of the main lipid components may lead to a disruption of the barrier function, and the substitution of the depleted lipid species might be of great significance to repair the disrupted SC.

Studies have shown that the application of complete physiological lipid mixtures containing CERs, CHOL and FFAs in the proper ratio facilitates the process of barrier recovery [73, 91]. Yang et al. [91] have shown that applying an optimal lipid mixture containing CHOL, CER, palmitate and linoleate $(4.3: 2.3: 1: 1.8)$ to an SC enhanced the its barrier function significantly after the barrier function 
Table 1. Common skin diseases associated with perturbations of SC lipids and corresponding alterations in SC lipid composition

\begin{tabular}{|c|c|c|c|c|c|}
\hline No. & Skin disease & Change in SC lipid composition & $\begin{array}{l}\text { Effect on barrier function } \\
\text { of the skin }\end{array}$ & Pathogenesis & $\begin{array}{l}\text { Reference } \\
(\mathrm{s})\end{array}$ \\
\hline 1 & $\mathrm{AD}$ & $\begin{array}{l}\text { Decreased levels of total CER } \\
\text { (CER[NP] and CER[EOS] reduced to a } \\
\text { greater extent), bound } \omega \text {-hydroxy- } \\
\text { ceramides and long-chain FFAs ( } 20-26 \\
\text { C atoms) including cis-6-hexadecenoic } \\
\text { acid; increased levels of CER[AS], } \\
\text { bound FFA and CHOL (but reduced } \\
\text { level of CHOL in old age); shorter- } \\
\text { chain-length CERs }\end{array}$ & $\begin{array}{l}\text { Significant increase in } \\
\text { TEWL; reduction in skin } \\
\text { hydration (dry skin) and } \\
\text { barrier function }\end{array}$ & $\begin{array}{l}\text { Upregulation of sphingomyelin deacylase and } \\
\text { glucosylceramide deacylase (which catalyzes } \\
\text { the hydrolysis of the N-acyl linkage of } \\
\text { sphingomyelin and glucosylceramide to } \\
\text { yield glucosylsphingosine and } \\
\text { sphingosylphosphorylcholine, respectively); } \\
\text { impaired conversion of LA to } \gamma \text {-LA; increased } \\
\text { level of ceramidase; decreased level of pSAP }\end{array}$ & $\begin{array}{l}{[15,17} \\
38,55,59 \\
60,70 \\
86-92]\end{array}$ \\
\hline 2 & Psoriasis & $\begin{array}{l}\text { Decreased level of total CER, but no } \\
\text { change to FFA level; Motta et al. [106] } \\
\text { reported decreased levels of CERs } \\
\text { with a phytosphingosine base with } \\
\text { concurrent increases in CERs with a } \\
\text { sphingosine base }\end{array}$ & $\begin{array}{l}\text { Progressive increase in } \\
\text { TEWL }\end{array}$ & $\begin{array}{l}\text { Decreased expression of serine } \\
\text { palmitoyltransferase and pSAP }\end{array}$ & $\begin{array}{l}{[2,13,55} \\
59,69,93 \\
94,106]\end{array}$ \\
\hline 3 & $\begin{array}{l}\text { Type } 2 \\
\text { Gaucher } \\
\text { disease }\end{array}$ & $\begin{array}{l}\text { Increased level of glucosylceramide- } \\
\text { to-CER ratio and altered lipid } \\
\text { organization }\end{array}$ & Ichthyosiform skin & $\begin{array}{l}\text { The level of glucocerebrosidase is significantly } \\
\text { reduced, and thus the conversion of } \\
\text { glucosylceramides to corresponding CERs } \\
\text { decreased }\end{array}$ & $\begin{array}{l}{[57,58,} \\
95]\end{array}$ \\
\hline 4 & $\begin{array}{l}\text { Sjögren- } \\
\text { Larsson } \\
\text { syndrome }\end{array}$ & $\begin{array}{l}\text { Increased levels of FFA and } \\
\text { membrane-bound CERs; decreased } \\
\text { levels of CER[EOS], CER[NP] and } \\
\text { CER[AP] }\end{array}$ & $\begin{array}{l}\text { TEWL not affected; } \\
\text { hyperkeratosis may } \\
\text { compensate the barrier } \\
\text { dysfunction }\end{array}$ & $\begin{array}{l}\text { An inborn error of lipid metabolism caused } \\
\text { by deficient activity of fatty alcohol; } \\
\text { NAD oxidoreductase }\end{array}$ & [96-98] \\
\hline 5 & $\begin{array}{l}\text { Lamellar } \\
\text { ichthyosis }\end{array}$ & $\begin{array}{l}\text { Decreased levels of acyl CERs } \\
\text { (especially CER[EOS]) and FFA }\end{array}$ & $\begin{array}{l}\text { Disruption of normal skin } \\
\text { barrier function }\end{array}$ & $\begin{array}{l}\text { A congenital recessive skin disorder caused by } \\
\text { mutation of 'transglutaminase' gene } 1\end{array}$ & {$[4,97,99]$} \\
\hline 6 & $\begin{array}{l}\text { X-linked } \\
\text { ichthyosis }\end{array}$ & $\begin{array}{l}\text { Increase in CHOL sulfate content } \\
\text { accompanied by decreased levels of } \\
\text { total neutral lipids and free sterols; no } \\
\text { change in sterol esters or total sterols }\end{array}$ & $\begin{array}{l}\text { Disruption of normal skin } \\
\text { barrier function }\end{array}$ & Deficiency in steroid sulfatase & {$[100]$} \\
\hline 7 & $\begin{array}{l}\text { Bullous } \\
\text { ichthyosiform } \\
\text { erythroderma }\end{array}$ & Decreased level of total CER & $\begin{array}{l}\text { Disruption of normal skin } \\
\text { barrier function }\end{array}$ & Abnormality of keratins 1 and 10 & {$[97,101]$} \\
\hline 8 & $\begin{array}{l}\text { Essential FFA } \\
\text { deficiency }\end{array}$ & $\begin{array}{l}\text { Reduced ratio of CER[EOS] linoleate } \\
\text { to CER[EOS] oleate }\end{array}$ & $\begin{array}{l}\text { Epidermal } \\
\text { hyperproliferation }\end{array}$ & Replacement of LA with oleic acid & {$[4,87]$} \\
\hline 9 & Acne vulgaris & Lower amounts of sphingolipids & $\begin{array}{l}\text { Impaired water barrier } \\
\text { function }\end{array}$ & Hyperkeratosis of the follicular epithelium & {$[102]$} \\
\hline 10 & Aged dry skin & Decreased CER levels & $\begin{array}{l}\text { Disturbance of SC lamellar } \\
\text { structure }\end{array}$ & Elevated ceramidase activity & {$[78]$} \\
\hline 11 & $\begin{array}{l}\text { Hypohidrotic } \\
\text { ectodermal } \\
\text { dysplasia }\end{array}$ & $\begin{array}{l}\text { Similar to AD, but significantly higher } \\
\text { level of CER[EOS] }\end{array}$ & $\begin{array}{l}\text { Lack of sweating ability, } \\
\text { and an often widely spread } \\
\text { dermatitis resembling AD }\end{array}$ & Genetic disorder & [103] \\
\hline 12 & Atopic eczema & Increase in short-chain CERs & Skin barrier dysfunction & Filaggrin, an epithelial barrier protein & {$[104]$} \\
\hline
\end{tabular}

had been disrupted via the extraction of nonpolar lipids by petroleum ether, acetone or some detergents or by removal of the whole SC by tape stripping. However, such an application showed no effect on skins treated with some detergents such as SDS, which the authors attributed to the protein denaturation effect of the surfactants and their penetration into the deeper nucleated layers of the epidermis, affecting their function. Imokawa et al. [73] reported that the application of a water-in-oil emulsion containing an SC lipid extract significantly improved the recovery of the barrier function of forearm skin which had been abrogated by SDS treatment. Holleran et al. [67] 
showed that the application of CERs to affected SC following a single topical application of $\beta$-chloro-L-alanine, an irreversible inhibitor of serine palmitoyltransferase, improved the barrier recovery process. Likewise, the topical coapplication of $\mathrm{CHOL}$ with lovastatin, a competitive inhibitor of HMG CoA reductase, after acetone treatment normalized the recovery of the barrier function [66]. Schröter et al. [45] showed that CER[AP], the short-chain phytosphingosine with a high polarity found on four $\mathrm{OH}$ groups, induces the formation of superstable lamellae. It has also been shown to be antiproliferative and proapoptotic in numerous cancer cell types in vitro, with the potential to act as an anticancer agent [92].

Studies have shown that a dietary intake of $\gamma$-LA could reverse epidermal hyperproliferation that occurred due to an essential FFA deficiency [93, 94]. Chung et al. [93] showed that the antiproliferative biopotency of this oil in the epidermis is primarily dependent upon the stereospecificity as well as the amount of $\gamma$-LA administered.

Bellew and del Rosso [95] reported that a promising result was obtained following the treatment of patients suffering from ichthyosis vulgaris with a physiological lipid-based barrier repair cream (EpiCeram ${ }^{\circledR}$ Skin Barrier Emulsion, containing CERs, CHOL and FFAs in a 3: 1:1 ratio; Promius Pharma LLC, Bridgewater, N.J., USA) if used in combination with a $12 \%$ ammonium lactate lotion (Lac-Hydrin; Ranbaxy Laboratories, Jacksonville, Fla., USA). According to the authors, at the 1-month follow-up visit, the patients had essentially completed resolution of ichthyotic scaling and xerosis. The cream was approved by the FDA in April 2006 for the treatment of burning and itching associated with dry skin conditions such as $\mathrm{AD}$, irritant contact dermatitis, radiation dermatitis and other dermatoses. In a study conducted by Proksch et al. [15], the application of an SC lipid mixture reduced the severity of stubborn-to-recalcitrant childhood $\mathrm{AD}$, normalized TEWL rates and replenished the lamellar membrane bilayers. In another study, the use of CER-containing cream showed a significant improvement of erythema, pruritus and fissuring compared with controls. Hence, there are some commercially available formulations intended for the direct replenishment of SC lipids in the SC, such as Lipobase ${ }^{\circledR}$ Repair Cream (Astellas Pharma Europe, Prague, Czech Republic), which contains CER[NS], CHOL and FFAs and is prescribed to moderate-to-severe dry skin conditions such as $\mathrm{AD}$, irritant and allergic contact dermatitis and chronic hand eczema [96]. Other commercial formulations in the market which contain CERs are CeraVe ${ }^{\circledR}$, TriCeram $^{\circledR}$, Atopiclair ${ }^{\circledR}$ and MimyX ${ }^{\circledR}$ Creams.

SC Lipid Replenishment Therapy

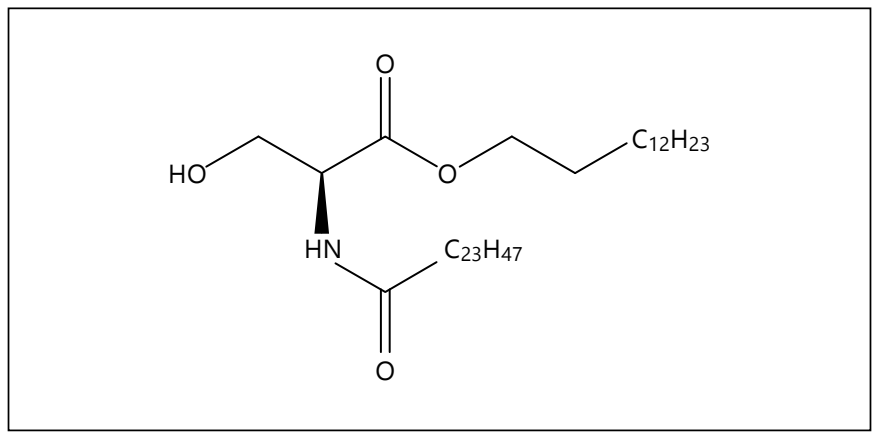

Fig. 5. Structure of $\mathrm{N}$-tetracosanoyl-(L)-serine tetradecyl ester.

Besides SC lipids, attempts were made to administer SC lipid analogues. Vavrova et al. [96] investigated the role of a cream containing a CER[NS] analogue, N-tetracosanoyl-(L)-serine tetradecyl ester (fig. 5; formed by replacement of the allylic hydroxyl NS by an ester group), on the barrier function of the skin. The results of the study, both ex vivo and in vivo, showed that the cream displays an excellent barrier-repairing activity in skin samples whose barrier function had been perturbed by either lipid extraction or tape stripping. Besides improving the barrier function of the skin, unlike the natural CERs, the CER analogue was synthesized by an inexpensive method that involves two steps. The latter also offers the advantage of minimizing the possibility of enzymatic inactivation of the CER.

Another interesting feature of the skin barrier is that the entire SC lipid species should be available in sufficient quantities. Increasing the concentration of unaffected lipids in affected or diseased skin may aggravate the problem [97]. Studies showed that in an SC whose integrity was disrupted by solvent treatment (e.g. acetone) or tape stripping, the application of key individual lipids (not in a physiologically rational mixture) delayed the barrier repair process, suggesting that there is a proper ratio between the SC lipids which must be present for the barrier repair to occur [91, 97]. In fact, Joo et al. [25] reported that the relative balance between the CER species is more important than the amount of CER in order to maintain the barrier function of the skin; that is, CERs with longer-chain FFA are more beneficial to the barrier function of the skin than short-chain CERs. Hence, a better understanding of the disease condition and careful replenishment of the depleted SC lipids are very important.

Some of the authors stated that for these lipids to be efficiently mingled with the SC, they should cross the SC 
layer and reach the SG-SC interface, where the lipids are arranged into meaningful lamellae $[4,6,16,17]$. Alternatively, they should penetrate into the deeper layers of the epidermis, whereby an uptake of the lipids by nucleated epidermal cell layers takes place, followed by a release of the lipid mixture into nascent lamellar bilayers in the SC interstices [15]. Therefore, their penetration into the deeper layers can be effected by using novel drug delivery systems. Sahle et al. $[98,99]$ developed different classes of colloidal carrier systems such as microemulsions, using polyglycerol fatty acid esters [98] and lecithin [99] as safe surfactants, which significantly enhanced the penetration of the lipids to the target site ex vivo [100].

Agents That Boost the Synthesis of SC Lipids in vivo or Minimize Their Degradation

CERs are synthesized, transformed and resynthesized in the process of keratinocyte differentiation. Their synthesis involves CER precursors and various enzymes such as serine palmitoyltransferase (see section 'Synthesis of SC lipids'). Therefore, compounds that may boost the activities of these enzymes increase the level of CERs in the SC. On the other hand, CERs are degraded by ceramidases including acid and alkaline ceramidases, and compounds that have inhibitory activities on these enzymes can produce an increased concentration of CERs in the SC [101]. Accordingly, the different compounds that are acting on these enzymes or have other CER synthesisboosting effects are summarized under this section.

Tanno et al. [102] showed that the topical application of nicotinamide and its derivatives such as 6-aminonicotinamide and nicotinic acid increased the biosynthesis of all CERs, glucosylceramides, sphingomyelin, FFAs and $\mathrm{CHOL}$ in the skin, which the authors attributed to the upregulation of some enzymes including serine palmitoyltransferase. It tends to decrease TEWL when applied to volunteers.

Ursolic acid is one of those agents that stimulate CER production in the human skin [77]. It is a nontoxic, naturally occurring triterpenoid that is found in a variety of medicinal plants and has antiaging properties by stimulating collagen production in cultured dermal fibroblasts and by reducing differentiation markers in cultured epidermal keratinocytes. The treatment of forearms of human volunteers with a lotion containing 0.3 or $1 \%$ ursolic acid liposomes resulted in an induction of CERs, with more increased levels of hydroxy CERs than of nonhydroxy CERs.
Rawlings et al. [103] reported that following L-lactic acid treatment of the skin, the level of total CER in the SC had increased significantly. According to the authors, the increase in CER biosynthesis was associated with the metabolism of lactic acid to acetyl CoA, which is utilized as a carbon source for lipid biosynthesis. It also increased the ratio of CER[EOS] linoleate to CER[EOS] oleate and keratinocyte proliferation. Dahl and Dahl [104] showed that a lotion containing lactic acid or lactate reduces the severity of xerosis.

In another study, the effect of Lipidessence ${ }^{\circledR}$, a hydrolysate of potato proteins, on the biosynthesis of sphingolipids was investigated [56]. The results showed that Lipidessence stimulates the biosynthesis of CHOL, phosphatidylcholine, phosphatidylserine and gangliosides, which results in a significant increase in the biosynthesis of FFAs, CERs, glucosylceramide and sphingomyelin.

Ishikawa et al. [11] demonstrated that the topical application of eucalyptus extract improves the water-holding and barrier function of the skin, which is associated with the active component macrocarpal A. According to the authors, macrocarpal A increases the level of CER in the SC following the expression of genes encoding serine palmitoyltransferase, glucosyltransferase, sphingomyelinase and glucocerebrosidase, which stimulate the biosynthesis of CER, glucosylceramide and sphingomyelin in keratinocytes.

Sodium dl- $\alpha$-tocopheryl-6-O-phosphate, a chemically stable hydrophilic derivative of dl- $\alpha$-tocopherol that can be used as a provitamin E supplement, is another compound that enhances the synthesis of CERs in vivo [101]. It was shown to induce the differentiation of keratinocytes by increasing the $\mathrm{Ca}^{2+}$ uptake of keratinocytes and stimulating the gene expression of CER synthetase. In addition, it has some antioxidative and anti-inflammatory activities that minimize the degradation of SC lipids.

The topical application of sake concentrate improved the barrier function of the SC in aged mice with a deteriorated transdermal function. The concentrate enhanced the synthesis of SC lipids, which the authors mainly associated with one of its main ingredients, $\alpha$-D-glucoside [105].

\section{Conclusions}

Skin is the largest organ of the body, whose major function is protection. The barrier function of the skin resides mainly in the $\mathrm{SC}$, particularly in the composition and organization of the SC lipid matrix, which mainly
Sahle/Gebre-Mariam/Dobner/Wohlrab/ Neubert 
contains CERs, FFAs and CHOL. Hence, the depletion or disturbance of any of those classes of lipid results in a disruption of the barrier function of the skin. Conversely, several skin diseases are associated with the depletion and disturbance of SC lipids. Hence, some studies suggest that the replenishment of those lipids by direct replacement of the missing lipids or enhancing their synthesis in the SC can be used to treat affected, aged or diseased skin. However, other studies have shown that the incorporation of unaffected SC lipids might result in a further disruption of the barrier function. Thus, understanding the various skin disease conditions and their associated changes in SC composition is of paramount importance for SC lipid replenishment therapy.
Hence, in this review, the changes in SC lipid composition in various disease conditions have been summarized along with the various approaches aimed at replenishing the depleted SC lipids. Furthermore, the organization, composition and synthesis of SC lipids and factors that affect the composition of SC lipids have also been reviewed.

\section{Acknowledgements}

Fitsum F. Sahle and Tsige Gebre-Mariam greatly acknowledge the financial support provided by the Alexander von Humboldt $(\mathrm{AvH})$ Foundation for their short stay at the Martin Luther University of Halle-Wittenberg in Germany.

\section{References}

1 El Maghraby GM, Barry BW, Williams AC: Liposomes and skin: from drug delivery to model membranes. Eur J Pharm Sci 2008;34: 203-222.

$\checkmark 2$ Holleran WM, Takagi Y, Uchida Y: Epidermal sphingolipids: metabolism, function, and roles in skin disorders. FEBS Lett 2006;580: 5456-5466.

- 3 Shah UU, Roberts M, Gul MO, Tuleu C, 12 Zhang L, Hellgren LI, Xu X: Enzymatic proBeresford MW; NIHR MCRN/Arthritis Research UK Paediatric Rheumatology Clinical Studies Group: Needle-free and microneedle drug delivery in children: a case for diseasemodifying antirheumatic drugs (DMARDs). Int J Pharm 2011;416:1-11.

-4 Bouwstra JA, Ponec M: The skin barrier in healthy and diseased state. Biochim Biophys Acta 2006;1758:2080-2095.

5 Bonte F, Pinguet P, Chevalier JM, Meybeck A: Analysis of all stratum corneum lipids by automated multiple development high-performance thin-layer chromatography. J Chromatogr B Biomed Appl 1995;664:311-316.

6 Bonte F, Pinguet P, Saunois A, Meybeck A, Beugin S, Ollivon M, Lesieur S: Thermotropic phase behavior of in vivo extracted human stratum corneum lipids. Lipids 1997;32:653660.

7 Ponec M, Weerheim A, Lankhorst P, Wertz P: New acylceramide in native and reconstructed epidermis. J Invest Dermatol 2003;120: 581-588.

8 de Jager MW, Gooris GS, Dolbnya IP, Bras W, Ponec M, Bouwstra JA: The phase behaviour of skin lipid mixtures based on synthetic ceramides. Chem Phys Lipids 2003;124:123134.

9 Hatfield RM, Fung LW: Molecular properties of a stratum corneum model lipid system: large unilamellar vesicles. Biophys J 1995;68: 196-207.

10 Groen D, Gooris GS, Ponec M, Bouwstra JA: Two new methods for preparing a unique stratum corneum substitute. Biochim Biophys Acta 2008;1778:2421-2429.

11 Ishikawa J, Shimotoyodome Y, Chen S, Ohkubo K, Takagi Y, Fujimura T, Kitahara T, Takema Y: Eucalyptus increases ceramide levels in keratinocytes and improves stratum corneum function. Int J Cosmet Sci 2012;34: $17-22$.

duction of ceramide from sphingomyelin. J Biotechnol 2006;123:93-105.

13 Farwanah H, Raith K, Neubert RH, Wohlrab $\mathrm{J}$ : Ceramide profiles of the uninvolved skin in atopic dermatitis and psoriasis are comparable to those of healthy skin. Arch Dermatol Res 2005;296:514-521.

14 Lampe MA, Williams ML, Elias PM: Human epidermal lipids: characterization and modulations during differentiation. J Lipid Res 1983;24:131-140.

15 Proksch E, Jensen JM, Elias PM: Skin lipids and epidermal differentiation in atopic dermatitis. Clin Dermatol 2003;21:134-144.

16 Weerheim A, Ponec M: Determination of stratum corneum lipid profile by tape stripping in combination with high-performance thin-layer chromatography. Arch Dermatol Res 2001;293:191-199.

17 Loden M: The skin barrier and use of moisturizers in atopic dermatitis. Clin Dermatol 2003;21:145-157.

-18 Mizutani Y, Mitsutake S, Tsuji K, Kihara A, Igarashi Y: Ceramide biosynthesis in keratinocyte and its role in skin function. Biochimie 2009;91:784-790.

19 de Jager MW, Gooris GS, Dolbnya IP, Ponec $\mathrm{M}$, Bouwstra JA: Modelling the stratum corneum lipid organisation with synthetic lipid mixtures: the importance of synthetic ceramide composition. Biochim Biophys Acta 2004;1664:132-140.

20 Kang L, Ho PC, Chan SY: Interactions between a skin penetration enhancer and the main components of human stratum corneum lipids isothermal titration calorimetry study. J Therm Anal Calorim 2006;83:27-30.

21 Hatta I, Ohta N, Inoue K, Yagi N: Coexistence of two domains in intercellular lipid matrix of stratum corneum. Biochim Biophys Acta 2006; 1758:1830-1836.

22 de Jager MW, Gooris GS, Dolbnya IP, Bras W, Ponec M, Bouwstra JA: Novel lipid mixtures based on synthetic ceramides reproduce the unique stratum corneum lipid organization. J Lipid Res 2004;45:923-932.

23 Norlén L, Gil IP, Simonsen A, Descouts P: Human stratum corneum lipid organization as observed by atomic force microscopy on Langmuir-Blodgett films. J Struct Biol 2007; 158:386-400.

24 Bonte F, Saunois A, Pinguet P, Meybeck A: Existence of a lipid gradient in the upper stratum corneum and its possible biological significance. Arch Dermatol Res 1997;289:7882.

25 Joo KM, Nam GW, Park SY, Han JY, Jeong HJ, Lee SY, Kim HK, Lim KM: Relationship between cutaneous barrier function and ceramide species in human stratum corneum. J Dermatol Sci 2010;60:47-50.

26 Jungersted JM, Hogh JK, Hellgren LI, Jemec GBE, Agner T: Ethnicity and stratum corneum ceramides. Br J Dermatol 2010;163:11691173.

27 Norlén L, Nicander I, Lundh Rozell B, Ollmar $S$, Forslind B: Inter- and intra-individual differences in human stratum corneum lipid content related to physical parameters of skin barrier function in vivo. J Invest Dermatol 1999;112:72-77.

28 Masukawa Y, Narita H, Shimizu E, Kondo N, Sugai Y, Oba T, Homma R, Ishikawa J, Takagi Y, Kitahara T, Takema Y, Kita K: Characterization of overall ceramide species in human stratum corneum. J Lipid Res 2008;49: 1466-1476. 
29 van Smeden J, Hoppel L, van der Heijden R, Hankemeier T, Vreeken RJ, Bouwstra JA: LC/ MS analysis of stratum corneum lipids: ceramide profiling and discovery. J Lipid Res 2011;52:1211-1221.

- 30 t'Kindt R, Jorge L, Dumont E, Couturon P, David F, Sandra P, Sandra K: Profiling and characterizing skin ceramides using reversedphase liquid chromatography-quadrupole time-of-flight mass spectrometry. Anal Chem 2012;84:403-411.

- 31 Farwanah H, Wohlrab J, Neubert RH, Raith $\mathrm{K}$ : Profiling of human stratum corneum ceramides by means of normal phase LC/APCIMS. Anal Bioanal Chem 2005;383:632-637.

32 Ramesh G, Das UN: Effect of free fatty acids on two-stage skin carcinogenesis in mice. Cancer Lett 1996;100:199-209.

-33 Ziboh VA, Miller CC, Cho Y: Metabolism of polyunsaturated fatty acids by skin epidermal enzymes: generation of antiinflammatory and antiproliferative metabolites. Am J Clin Nutr 2000;71:361S-366S.

- 34 Hinder A, Schmelzer CEH, Rawlings AV, Neubert RHH: Investigation of the molecular structure of the human stratum corneum ceramides [NP] and [EOS] by mass spectrometry. Skin Pharmacol Physiol 2011;24:127-135.

35 Ansari MNA, Nicolaides N, Fu HC: Fatty acid composition of the living layer and stratum corneum lipids of human sole skin epidermis. Lipids 1970;5:838-845.

-36 Terashi H, Izumi K, Rhodes LM, Marcelo CL: Human stratified squamous epithelia differ in cellular fatty acid composition. J Dermatol Sci 2000;24:14-24.

- 37 Jiang WG, Bryce RP, Horrobin DF: Essential fatty acids: molecular and cellular basis of their anti-cancer action and clinical implications. Crit Rev Oncol Hematol 1998;27:179209.

38 Takigawa H, Nakagawa H, Kuzukawa M, Mori H, Imokawa G: Deficient production of hexadecanoic acid in the skin is associated in part with the vulnerability of atopic dermatitis patients to colonization by Staphylococcus aureus. Dermatology 2005;211:240-248.

-39 Chen X, Kwak S, Lafleur M, Bloom M, Kitson $\mathrm{N}$, Thewalt J: Fatty acids influence 'solid' phase formation in models of stratum corneum intercellular membranes. Langmuir 2007; 23:5548-5556.

40 Brody I: A light and electron microscopy study of normal human stratum corneum with particular reference to the intercellular space. Ups J Med Sci 1989;94:29-45.

-41 Bouwstra JA, Dubbelaar FE, Gooris GS, Ponec M: The lipid organisation in the skin barrier. Acta Derm Venereol Suppl (Stockh) 2000;208:23-30.

$\checkmark 42$ Forslind B: A domain mosaic model of the skin barrier. Acta Derm Venereol 1994;74: $1-6$.

-43 Kiselev MA, Ryabova NY, Balagurov AM, Dante S, Hauss T, Zbytovska J, Wartewig S, Neubert RH: New insights into the structure and hydration of a stratum corneum lipid model membrane by neutron diffraction. Eur Biophys J 2005;34:1030-1040.

44 ten Grotenhuis E, Demel RA, Ponec M, Boer DR, van Miltenburg JC, Bouwstra JA: Phase behavior of stratum corneum lipids in mixed Langmuir-Blodgett monolayers. Biophys J 1996;71:1389-1399.

45 Schröter A, Kessner D, Kiselev MA, Hauss T, Dante S, Neubert RH: Basic nanostructure of stratum corneum lipid matrices based on ceramides [EOS] and [AP]: a neutron diffraction study. Biophys J 2009;97:1104-1114.

46 Norlén L: Skin barrier structure and function: the single gel phase model. J Invest Dermatol 2001;117:830-836.

47 Kiselev MA: Conformation of ceramide 6 molecules and chain-flip transitions in the lipid matrix of the outermost layer of mammalian skin, the stratum corneum. Crystallogr Rep 2007;52:525-528.

48 Kessner D, Ruettinger A, Kiselev MA, Wartewig S, Neubert RH: Properties of ceramides and their impact on the stratum corneum structure. Part 2. Stratum corneum lipid model systems. Skin Pharmacol Physiol 2008; 21:58-74.

49 Norlén L: Molecular structure of the SC lipids in vivo. Skin Forum 12th Ann Meet, Frankfurt, 2011.

50 Boncheva M, Damien F, Normand V: Molecular organization of the lipid matrix in intact stratum corneum using ATR-FTIR spectroscopy. Biochim Biophys Acta 2008;1778:13441355.

51 Caussin J, Gooris GS, Bouwstra JA: FTIR studies show lipophilic moisturizers to interact with stratum corneum lipids, rendering the more densely packed. Biochim Biophys Acta 2008;1778:1517-1524.

52 Bouwstra JA, Honeywell-Nguyen PL: Skin structure and mode of action of vesicles. Adv Drug Deliv Rev 2002;54(suppl 1):S41-S55.

53 Caussin J, Gooris GS, Janssens M, Bouwstra JA: Lipid organization in human and porcine stratum corneum differs widely, while lipid mixtures with porcine ceramides model human stratum corneum lipid organization very closely. Biochim Biophys Acta 2008; 1778: 1472-1482.

54 Corbe E, Laugel C, Yagoubi N, Baillet A: Role of ceramide structure and its microenvironment on the conformational order of model stratum corneum lipids mixtures: an approach by FTIR spectroscopy. Chem Phys Lipids 2007;146:67-75.

55 Hong KK, Cho HR, Ju WC, Cho Y, Kim NI: A study on altered expression of serine palmitoyltransferase and ceramidase in psoriatic skin lesion. J Korean Med Sci 2007;22:862867.

56 Popa I, Bennaceur K, Abdul-Malak N, Perrier E, Schmitt D, Portoukalian J: Studies of compounds that enhance sphingolipid metabolism in human keratinocytes. Int J Cosmet Sci 2006;28:53-59.

57 Uchida Y, Hara M, Nishio H, Sidransky E, Inoue S, Otsuka F, Suzuki A, Elias PM, Holleran
WM, Hamanaka S: Epidermal sphingomyelins are precursors for selected stratum corneum ceramides. J Lipid Res 2000;41:20712082.

58 Holleran WM, Ginns EI, Menon GK, Grundmann JU, Fartasch M, McKinney CE, Elias PM, Sidransky E: Consequences of $\beta$-glucocerebrosidase deficiency in epidermis: ultrastructure and permeability barrier alterations in Gaucher disease. J Clin Invest 1994;93:1756-1764.

59 Alessandrini F, Stachowitz S, Ring J, Behrendt $\mathrm{H}$ : The level of prosaposin is decreased in the skin of patients with psoriasis vulgaris. J Invest Dermatol 2001;116:394-400.

60 Imokawa G: A possible mechanism underlying the ceramide deficiency in atopic dermatitis: expression of a deacylase enzyme that cleaves the $\mathrm{N}$-acyl linkage of sphingomyelin and glucosylceramide. J Dermatol Sci 2009; 55:1-9.

61 Holleran WM, Gao WN, Feingold KR, Elias PM: Localization of epidermal sphingolipid synthesis and serine palmitoyl transferase activity: alterations imposed by permeability barrier requirements. Arch Dermatol Res 1995;287:254-258.

62 Holleran WM, Takagi Y, Menon GK, Legler G, Feingold KR, Elias PM: Processing of epidermal glucosylceramides is required for optimal mammalian cutaneous permeability barrier function. J Clin Invest 1993;91:16561664.

63 Grubauer G, Elias PM, Feingold KR: Transepidermal water loss: the signal for recovery of barrier structure and function. J Lipid Res 1989;30:323-333.

64 Proksch E, Elias PM, Feingold KR: Regulation of 3-hydroxy-3-methylglutaryl-coenzyme A reductase activity in murine epidermis: modulation of enzyme content and activation state by barrier requirements. J Clin Invest 1990; 85:874-882.

65 Mao-Qiang M, Elias PM, Feingold KR: Fatty acids are required for epidermal permeability barrier function. J Clin Invest 1993;92:791798.

66 Feingold KR, Man MQ, Menon GK, Cho SS, Brown BE, Elias PM: Cholesterol synthesis is required for cutaneous barrier function in mice. J Clin Invest 1990;86:1738-1745.

67 Holleran WM, Man MQ, Gao WN, Menon GK, Elias PM, Feingold KR: Sphingolipids are required for mammalian epidermal barrier function: inhibition of sphingolipid synthesis delays barrier recovery after acute perturbation. J Clin Invest 1991;88:1338-1345.

68 Mao-Qiang M, Feingold KR, Elias PM: Inhibition of cholesterol and sphingolipid synthesis causes paradoxical effects on permeability barrier homeostasis. J Invest Dermatol 1993; 101:185-190.

69 Lew BL, Cho Y, Kim J, Sim WY, Kim NI: Ceramides and cell signaling molecules in psoriatic epidermis: reduced levels of ceramides, PKC- $\alpha$, and JNK. J Korean Med Sci 2006;21: 95-99. 
70 Jacobs RJ: Depleted skin barrier replenishing skin creams composition and method of application. US Patent No US 10/426,493. 2004.

-71 Grubauer G, Feingold KR, Harris RM, Elias PM: Lipid content and lipid type as determinants of the epidermal permeability barrier. J Lipid Res 1989;30:89-96.

72 Kwak S, Brief E, Langlais D, Kitson N, Lafleur $M$, Thewalt J: Ethanol perturbs lipid organization in models of stratum corneum membranes: an investigation combining differential scanning calorimetry, infrared and ${ }^{2} \mathrm{H}$ NMR spectroscopy. Biochim Biophys Acta 2012;1818:1410-1419.

73 Imokawa G, Akasaki S, Minematsu Y, Kawai M: Importance of intercellular lipids in waterretention properties of the stratum corneum: induction and recovery study of surfactant dry skin. Arch Dermatol Res 1989;281:45-51.

-74 Jenerowicz D, Silny W, Danczak-Pazdrowska A, Polanska A, Osmola-Mankowska A, OlekHrab K: Environmental factors and allergic diseases. Ann Agric Environ Med 2012;19: 475-481.

75 Rawlings AV, Matts PJ: Stratum corneum moisturization at the molecular level: an update in relation to the dry skin cycle. J Invest Dermatol 2005;124:1099-1110.

76 Rogers J, Harding C, Mayo A, Banks J, Rawlings A: Stratum corneum lipids: the effect of ageing and the seasons. Arch Dermatol Res 1996;288:765-770.

-77 Both DM, Goodtzova K, Yarosh DB, Brown DA: Liposome-encapsulated ursolic acid increases ceramides and collagen in human skin cells. Arch Dermatol Res 2002;293:569-575.

-78 Jin K, Higaki Y, Takagi Y, Higuchi K, Yada Y, Kawashima M, Imokawa G: Analysis of $\beta$-glucocerebrosidase and ceramidase activities in atopic and aged dry skin. Acta Derm Venereol 1994;74:337-340.

-79 Altemus M, Rao B, Dhabhar FS, Ding W, Granstein RD: Stress-induced changes in skin barrier function in healthy women. J Invest Dermatol 2001;117:309-317.

-80 Al'Abadie MS, Kent GG, Gawkrodger DJ: The relationship between stress and the onset and exacerbation of psoriasis and other skin conditions. Br J Dermatol 1994;130:199-203.

-81 Kiecolt-Glaser JK, Marucha PT, Malarkey WB, Mercado AM, Glaser R: Slowing of wound healing by psychological stress. Lancet 1995;346:1194-1196.

-82 Gupta MA, Gupta AK: Psychodermatology: an update. J Am Acad Dermatol 1996;34: 1030-1046.
83 Marucha PT, Kiecolt-Glaser JK, Favagehi M: Mucosal wound healing is impaired by examination stress. Psychosom Med 1998;60:362365.

84 Vavrova K, Zbytovska J, Palat K, Holas T, Klimentova J, Hrabalek A, Dolezal P: Ceramide analogue 14S24 ((S)-2-tetracosanoylamino3-hydroxypropionic acid tetradecyl ester) is effective in skin barrier repair in vitro. Eur J Pharm Sci 2004;21:581-587.

85 Farwanah H, Neubert R, Zellmer S, Raith K Improved procedure for the separation of major stratum corneum lipids by means of automated multiple development thin-layer chromatography. J Chromatogr B Analyt Technol Biomed Life Sci 2002;780:443-450.

86 Ishikawa J, Narita H, Kondo N, Hotta M, Takagi Y, Masukawa Y, Kitahara T, Takema Y, Koyano S, Yamazaki S, Hatamochi A: Changes in the ceramide profile of atopic dermatitis patients. J Invest Dermatol 2010;130:25112514.

87 Macheleidt O, Kaiser HW, Sandhoff K: Deficiency of epidermal protein-bound $\omega$-hydroxyceramides in atopic dermatitis. J Invest Dermatol 2002;119:166-173.

88 Cho Y, Lew BL, Seong K, Kim NI: An inverse relationship between ceramide synthesis and clinical severity in patients with psoriasis. J Korean Med Sci 2004;19:859-863.

89 Holleran WM, Feingold KR, Man MQ, Gao WN, Lee JM, Elias PM: Regulation of epidermal sphingolipid synthesis by permeability barrier function. J Lipid Res 1991;32:11511158 .

90 Menon GK, Feingold KR, Elias PM: Lamellar body secretory response to barrier disruption. J Invest Dermatol 1992;98:279-289.

91 Yang L, Mao-Qiang M, Taljebini M, Elias PM, Feingold KR: Topical stratum corneum lipids accelerate barrier repair after tape stripping, solvent treatment and some but not all types of detergent treatment. Br J Dermatol 1995; 133:679-685.

92 Stover TC, Sharma A, Robertson GP, Kester M: Systemic delivery of liposomal short-chain ceramide limits solid tumor growth in murine models of breast adenocarcinoma. Clin Cancer Res 2005;11:3465-3474.

93 Chung S, Kong S, Seong K, Cho Y: $\gamma$-Linolenic acid in borage oil reverses epidermal hyperproliferation in guinea pigs. J Nutr 2002;132: 3090-3097.

94 Barre DE: Potential of evening primrose, borage, black currant, and fungal oils in human health. Ann Nutr Metab 2001;45:47-57.

$\checkmark 95$ Bellew S, del Rosso JQ: Overcoming the barrier treatment of ichthyosis: a combinationtherapy approach. J Clin Aesthet Dermatol 2010;3:49-53.
$\$ 96$ Vavrova K, Hrabalek A, Mac-Mary S, Humbert P, Muret P: Ceramide analogue 14S24 selectively recovers perturbed human skin barrier. Br J Dermatol 2007;157:704-712.

$\$ 97$ Man MM, Feingold KR, Thornfeldt CR Elias PM: Optimization of physiological lipid mixtures for barrier repair. J Invest Dermatol 1996;106:1096-1101.

-98 Sahle FF, Metz H, Wohlrab J, Neubert RH Polyglycerol fatty acid ester surfactantbased microemulsions for targeted delivery of ceramide AP into the stratum corneum: formulation, characterisation, in vitro release and penetration investigation. Eur J Pharm Biopharm 2012;82:139-150.

-99 Sahle FF, Metz H, Wohlrab J, Neubert RH Lecithin-based microemulsions for targeted delivery of ceramide AP into the stratum corneum: formulation, characterizations, and in vitro release and penetration studies. Pharm Res 2013;30:538-551.

100 Sahle FF, Wohlrab J, Neubert RH: Controlled penetration of ceramides into and across the stratum corneum using various types of microemulsions and formulation associated toxicity studies. Eur J Pharm Biopharm 2014;86:244-250.

101 Kato E, Takahashi N: Improvement by sodium dl- $\alpha$-tocopheryl-6-O-phosphate treatment of moisture-retaining ability in stratum corneum through increased ceramide levels. Bioorg Med Chem 2012;20:3837-3842.

102 Tanno O, Ota Y, Kitamura N, Katsube T, Inoue S: Nicotinamide increases biosynthesis of ceramides as well as other stratum corneum lipids to improve the epidermal permeability barrier. Br J Dermatol 2000;143: 524-531.

103 Rawlings AV, Davies A, Carlomusto M, Pillai S, Zhang K, Kosturko R, Verdejo P, Feinberg C, Nguyen L, Chandar P: Effect of lactic acid isomers on keratinocyte ceramide synthesis, stratum corneum lipid levels and stratum corneum barrier function. Arch Dermatol Res 1996;288:383-390.

104 Dahl MV, Dahl AC: $12 \%$ lactate lotion for the treatment of xerosis: a double-blind clinical evaluation. Arch Dermatol 1983;119:27-30.

105 Nakahara M, Mishima T, Hayakawa T: Effect of a sake concentrate on the epidermis of aged mice and confirmation of ethyl $\alpha-\mathrm{D}$ glucoside as its active component. Biosci Biotechnol Biochem 2007;71:427-434.

106 Motta S, Monti M, Sesana S, Caputo R, Carelli S, Ghidoni R: Ceramide composition of the psoriatic scale. Biochim Biophys Acta 1993;1182:147-151. 